number of cases of cancer of the uterus and breast. Lyon. considers that the figures support the idea that the peculiar diet of the Germans is responsible for the high rate amongst them. ${ }^{2}$

After a review of such information as has been given me since my paper appeared in 'THE LANOET of August 31st I do not think that the hypothesis I submitted for examination has been seriously shaken, and it seems to receive a certain small measure of support from some of the facts stated-e.g., the freedom of the Hindoos from cancer and their carefulness to boil their milk and cleanse their skins, and by the apparent relationship to diet of some kind indicated by Dr. Lyon's Buffalo figures.

Sept. 30th, 1901.

I am, Sirs, yours faithfully,

C. B. KEETLEY.

\section{THE COMING ELECTION TO THE GENERAL MEDICAL COUNCIL.}

\section{To the Editors of THE LANCET.}

SrRS,-Acting as secretary pro tem. I beg to inform you that a meeting of the profession in the north is being arranged in connexion with the approaching election to the General Medical Council. The Cunty of Durham Medical Union has taken the initiative and has already been promised the coöperation of the North of England Branch of the British Medical Association, the Northumberland and Newcastle Medical Association, and the Gateshead Medical Association. There is no doubt that the other associations in the district will assist in making the meeting large and representative. In order to save the time of candidates for the Council and to give them an opportunity of easily reaching as large a number as possible of the electors, it is proposed to ask every candidate to come to the proposed meeting which will be arranged for a date in October. This meeting, which will be held in Newcastle, will offer to each candidate an opportunity to state his views and make the personal acquaintance of a section of the electors. The meeting will, we hope, have the effect of increasing the interest in the election and of ensuring a good local vote.

$$
\text { I am, Sirs, yours faithfully, }
$$

Gateshead, Sept. 27th, 1901. ALFRED COS.

\section{"APPENDICITIS."}

\section{To the Editors of THE LANCET.}

SIRs,-Having read with considerable interest Mr. F. G. Lloyd's excellent article on Appendicitis, some General Remarks on its Pathology and Treatment. which appeared in THE LANCET of Sept. 21st, p. 788, it has occurred to me that he has passed over what may be one of the primary causes of this not uncommon trouble. For some time past it has been in my mind that the starting-point is due to defective digestion brought about frequently by imperfect mastication of food. 'The undigested portions decomposing' in the bowel generate gas which distends the crecum; this distension naturally opens wide the orifice of the appendix vermiformis, into which fæcal substance is allowed easily to enter. The gas passing away and the orifice contracting the contained matter is thus retained. The appendix, endeavouring to expel it by its vermicular movements, squeezes out the fluid parts, but the more solid portion remains behind and becomes the concretion which is so frequently found as the cause of the inflammation which has necessitated operation. In many cases the primary attack subsides until another crecal distension takes place with a recurrent "appendicitis," and in one of these attacks of distension it is easily conceivable that a foreign body, such as any of those so well illustrated in the Johns Hopkins Hospital Bulletin for January-March, 1899, may enter and give rise to violent inflammation and be found at the time of operation. In a recent case in my practice a frcal concretion of the shape of, and as large as, a monkey-nut was discovered together with two cherry-stones. The patient underwent operation; the appendix was excised and he made a good recovery. Whether this suggestion is original I am not prepared to say, but so far I have not seen attention drawn toit as a cause.

I am, Sirs, yours faithfully,

HERBER' J. CAPON.

Upper George-street, W., Sept. 29th, 1901.

2 Brit. Mod. Jour., Sept. 21st, 1901.

\section{"WORKHIOUSE NURSING."}

To the liditors of THE LANCET.

SIJRS, - J'hrough the courtesy of Miss Louisa Twining I hare been able to confirm that which I had previously snspectedviz., that Mr. F. R. Humphreys has annexed and labeled as "my (Mr. Humphreys's) scheme" the plan formulated by Miss Twining and published by her in July, 1901. I have no intention, therefore, of cliscussing the matter further with Mr. Humphreys, but as that gentleman has represented me as holding views entirely contrary to my expressed opinions I must ask you to allow me to correct his statements.

In my last letter, after stating that nurses in the smaller infirmaries were not well paid and were badly governed. I expressed the opinion that with adequate salaries and proper government there wonld be no lack of good nurses. In the face of this Mr. Humphreys accuses me of holding exactly diverse opinions and bombards me with extracts trom the reports of Local Government Board inspectors, with every one of which I entirely agree. Either Mr. Humphreys is obtuse or he represents me as holding opinions contrary to the actual facts that he may have the easy advantage of controverting them. Mr. Humphreys also represents me as advocating the employment of untrained nurses, whereas I expressly stated that I admitted the advisability of having highly trained nurses, a statement which Mr. Humphrefs has omitted to quote; and I endeavoured to make it perfectly plain that the suggested massing together of the sick would not supply the requisite material for the efficient training of nurses, but would result in the production of a fraudulently hall-marked article. Mr. Humphreys accuses me of contradicting myself when I say that the larger inlirmaries train their nurses thoroughly. It is difticult to argue with one who knows so little of his subject as to be unable to distinguish between a large infirmary situated in the midst of its district and containing many acute medical and surgical cases and that of a small country infirmary miles away from the homes of its patients.

The term "pioneer work" as applied to the efforts of the Workhouse Infirmary Nursing Association is simply a cant phrase, and the fact remains that it cornmitted suicide because it had become so distrusted, and had by the under hand methorls of its nurses excited so much antagonism that it could no longer continue its career.

$1 \mathrm{am}$, Sirs, yours faithfully,

F. S. Toogood, M.D. Lond.

Sept. 3Cth, 1901

Iredical Superintendent, Lewisham Infirmary, S.E.

\section{"THE PROSPECT OF CURE IN CANCER." \\ To the Editors of THE LANCET.}

SIRS,-In confirmation of the views expressed by $\mathrm{Dr}$ Horace Manders in THE LANCET of Sept. 28th may I be allowed to state that it has recently been my privilege to be a disinterested, and I hope impartial, observer of a number of cases of cancer and of pulmonary tuberculosis which are at the present time undergoing treatment without the aid of drugs at the hand of a physician and an expert in electrical science, whose desire it is that their names should for the moment not be divulged?

The cases of tuberculosis are all in the stage of cavitation; those of cancer have, with one exception, been pronounced by authorities well known to the medical world to be hopeless. of all those which have been more than a week under treatment $I$ am in a position to say that, both as to local conditions and general health, they are in a state which, to all appearance, is one of imminent cure. Very shortly-probably before many weeks have passed-you will be invited to give to the medical profession a full statement of these cases and a detailed account of the means and methods which are being brought to bear on their treatment.

Sept. 30th, 1901.

I am, Sirs, yours faithfully,

W. BEZLY THORNE.

\section{THE OUTBREAK OF SMALL-POX IN SOUTH AUSTRALIA.}

To the Editors of THE LANCET.

SIRS, - The account of the outbreak of small-pox by your Australian correspondent in THE LANCET of July 27th, p. 253, is correct in the main but erroneous in some particulars, especially where it states, "When the Adelaide passenger 
had been 11 days in quarantine Dr. Ramsay Smith advised that they should be released and kept under surveillance." This is not so. What I did was to recommend the removal to comfortable quarantine quarters elsewhere of certain persons sick, but not from smäll-pox, who had been certified as medically unfit for detention on Torrens Island. This removal was accomplished as soon as the weather permitted. These persons, like the other contacts, served their legal period of detention, for whatever my personal views of quarantine in general may be I have to carry out the laws in particular that refer to this State. The statement that a constable developed the disease at Adelaide is incorrect.

The muddles your correspondent refers to existed (1) in the imaginations and reports of some newspaper correspondents who knew neither laws nor science; (2) the misstatements founded thereon by an Adelaide medical gentleman; and (3) in an alleged interview of a newspaper correspondent with the president of the Board of Health at Sydney who afterwards affirmed that he had never given any foundation whatever for the statements regarding blundering at Adelaide attributed to him in that interview. Unfounded criticisms of this sort regarding official action are ignored when they appear in the lay press; but they should not be allowed to gain currency by being repeated unchallenged in professional journals. - T have the honour to be, Sirs, Your obedient servant,

W. RaMSAY SMITH, M.B., C.M., B.Sc. Edin

President of the Central Board of Health for South Australia. Adelaide, August 28th, 1901.

\section{THE OPEN-AIR TREATMENT OF TUBERCULOSIS. \\ To the Editors of THE LANCET.}

SIRS, - In a previous communication to you-published on May 20th, 1899 , p. $1409-\mathbf{I}$ recorded a case of early phthisis in a young woman which showed marked improvement and eventual recovery under treatment by high feeding and fresh air. I have recently seen this case again and the improvement has been permanent. The patient looks the picture of health, takes long bicycle rides, and has neither felt sick nor sorny during the time-a period of two years and four months.

As I mentioned then, tuberculosis in any form is quite a rarity in this district and hitherto only a few cases, comparatively speaking, have come under one's care from other places, and from various causes they generally stay but a short time; unfortunately, too, one hears little or nothing of their subsequent history, and it is satisfactory to find as above that the treatment is, at any rate in some, a means of permanent cure. All early cases invariably show marked improvement, and $I$ have now a patient who is responding to treatment in a fashion astonishing both to her relatives and myself. The patient, a married woman, aged 42 years, was ordered away by her medical man for phthisis of the lung, as her best chance. The lung is affected as low as the nipple and the drenching sweats, loathing of food, anæmia, and utter listlessness combined made as sorry a picture as one need wish to see. Walking and movement caused much distress. The house she is staying at is on clay in the lowest-lying part of the village and the situation is not the most suitable for the open-air treatment. However, the trial has been most satisfactory, as in 15 days she has gained a stone in weight with corresponding improvement in every other respect, including the ability to walk quite a fair distance without trouble. It is too early to give a good definite prognosis, but so far the satisfactory progress of the case speaks well for high feeding and fresh air in suitable cases even in private houses not in the best of positions. I feel sure that the enormous rise and fall in the tide here by causing a continual change of air is responsible not only for the healthy condition of the population, but also for the happy results obtainable in early cases of phthisis. I am, Sirs, yours faithfully,

GEORGE BoYD, M.R.C.S. Eng., L.R.C.P. Lond, Portishead, Somerset, Sept. 28th, 1901.

\section{"FRENCH AND BRITISH POSTAL MEDICAL SERVICES : A COMPARISON."}

To the Editors of THE LANCET.

SIRS,-Your Special Commissioner in his article in THE LANCE' of Sept. 2 Ist, p. 806, upon the above subject has contributed an extremely well-informed and interesting account, so far, at any rate, as London is concerned. May
I, as postal medical officer to a large and important London district, make a few observations thereon?

Of the French system I know nothing beyond what I have read in your Commissioner's admirable article, but I gather that part of the French system at least is of comparatively recent establishment (May 19th, 1900), and whether a sufficient length of time has elapsed to prove its efficiency and whether the medical service there works as smoothly and easily as the easy flow of your Commissioner's remarks appears to suggest I cannot say, but $I$ think it at all events merits the query. The system is certainly ingenious and, compared with our " rough-and-ready method," which is simple if not original, looks somewhat complicated.

"The most serious defect of the British system," says your Commissioner, "is that the $8 s .6 d$. per annum has to meet every conceivable circurnstance that may arise." "If a serious surgical operation is needed this must be performed, \&c., \&c." Theoretically this may be so; $8 s .6 d$. per oflicer per aunum is paid for medical attendance, but surely for medical attendance only so far as a medical officer's ability goes. The postal authorities certainly do not expect them to undertake serious surgical operations. There is no such stipulation made in the instructions issued to medical officers on appointment they are simply required to do their best for their patients in promoting their recovery and their speedy return to duty. Ubviously their best would not be the undertaking of a serious operation of which they have had probably little or no experience. I should be exceedingly surprised also to learn that they (the postal authorities) have ever required a medical officer to provide a surgeon for such operation at his own expense. Not many surgeons, I imagine, would care to undertake a serious operation in the home of a postman in London with all the attendant difficulties in the matter of space, ventilation, cleanliness, and nursing, and I cloubt whether competent surgeons could ever be induced to visit and to operate at anything like the scale of fees mentioned by your Commissioner. We have different ideas as to operation fees here in England.

And why should not postal officials be the recipients of hospital charity if necessary? They surely have as much right to it according to their station in life as other members of the community. In most offices they subscribe to the Hospital Saturday Fund, and the late Postmaster-General was in the habit of specially subscribing to certain London hospitals, so we were given to understand, because he recognised the fact that from time to time cases arose amongst the officials that could only be treated satisfactorily in hospital. Only such cases as really require hospital attention are sent there and hospital authorities at least know they are proper cases for relief. In an experience of eight years I have never known any difficulty arise in such cases.

Again, your Commissioner says: "There is such a delightful and lazy simplicity about the 8s. 6d." Why lazy? I think it would strike most people as a simple, practical, common-sense method of remuneration for services, generally admitted, I believe, to be exceedingly well performed. Why should one complain if a Government Department for once in a way does do a practical commonsense stroke of business? Government does not often get credit for so doing. Your Commissioner says that it is not common-sense and he would introduce the intricacy and elaborate detail of the French system. But it does not follow that a system which may answer admirably in Paris would be equally applicable in London. Some few years ago a commission was appointed to investigate post-office methods and grievances of officials, and the question of officials being attended by the medical officer of their own home district was then raised and, after consideration, the idea was rejected. The postal medical officer's duties do not merely consist of attendance upon the sick. He bas to be in touch with his district offices, he has to be familiar with their working arrangements, and their sanitary condition is his special care; he is more or less acquainted with the officers employed there and he has to make reports, suggestions, and give advice from time to time concerning them and their duties. If an official is being attended privately and the illness is of any considerable duration it is the medical officer's duty to make himself acquainted with the case and to be prepared to give an opinion upon it. He is to a certain extent responsible for the amount of sickness, or, at all events, is expected to be able to account for any excess of sickness in his district. These are his duties and responsibilities; they mean a great deal more than mere sick attendance. The Department recognises that much is required 